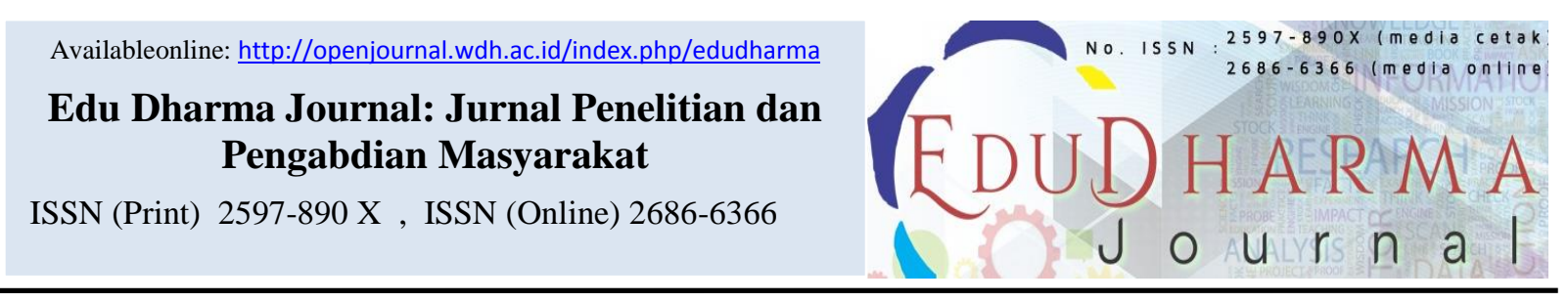

\title{
PENGARUH PENDIDIKAN HAND HYGIENE TERHADAP PERILAKU CUCI TANGAN ENAM TAHAP PADA KELUARGA PASIEN DI UNIT RAWAT INAP RUMAH SAKIT dr. SITANALA TANGERANG
}

Gita Ayuningtyas*, Nita Ekawati, Rahma Puspitasari

STIKes Widya Dharma Husada Tangerang, Jl. Pajajaran No. 1 Pamulang, Tangerang Selatan 15417, Indonesia

\begin{tabular}{|c|c|}
\hline ARTICLE INFORMATION & $\begin{array}{llllllll}A & B & S & T & R & A & C & T\end{array}$ \\
\hline $\begin{array}{l}\text { *Corresponding Author } \\
\text { Gita Ayuningtyas } \\
\text { E-mail: gitaayuningtyas@wdh.ac.id }\end{array}$ & $\begin{array}{l}\text { Nosocomial contamination is a disease that shows up in patients while } \\
\text { going through treatment in a clinic or other wellbeing office that doesn't } \\
\text { exist when the patient enters. Every patient undergoing treatment at the } \\
\text { hospital is at risk of being exposed to nosocomial infections. The patient's } \\
\text { family can be an intermediary that can transmit the infection Hand }\end{array}$ \\
\hline $\begin{array}{l}\text { Keywords: } \\
\text { Education_1 } \\
\text { Hand washing_2 } \\
\text { Behavior_3 } \\
\text { Patient's family_4 }\end{array}$ & $\begin{array}{l}\text { Errors in proper hand washing are considered the main cause of } \\
\text { nosocomial infections in health services. Providing handwashing } \\
\text { education to the patient's family must be carried out by the entire } \\
\text { community of the hospital. Increasing the patient's family's understanding } \\
\text { of six-step washing can affect handwashing behavior. The purpose behind } \\
\text { the examination was to decide the impact of hand washing schooling on } \\
\text { six-venture handwashing conduct in the patient's family. The examination } \\
\text { strategy utilized a quantitative methodology with a cross sectional plan } \\
\text { did on } 198 \text { responden utilizing surveys and perceptions. The outcomes } \\
\text { showed that most of respondents matured } 36-45 \text { years (41\%), female sex } \\
110 \text { (56\%), training at the secondary school level as much as } 77 \text { (39\%), } \\
\text { and experience with handwashing instruction expressed } 90 \% \text { of } \\
\text { respondents had been uncovered. It tends to be closed from the chi- } \\
\text { square test that there was a critical impact among hand washing } \\
\text { instruction on six-venture handwashing conduct in the patient's family (p- } \\
\text { value = } 0.046) \text {. Suggestions can be given, namely nurses need to improve } \\
\text { the provision of six-step hand washing education to the patient's family } \\
\text { consistently and continuously. }\end{array}$ \\
\hline $\begin{array}{l}\text { Kata Kunci: } \\
\text { Edukasi_1 } \\
\text { Cuci tangan_2 } \\
\text { Perilaku_3 } \\
\text { Keluarga pasien_4 }\end{array}$ & $\begin{array}{l}\text { A B S T R A K } \\
\text { Infeksi nosokomial mengacu pada infeksi yang terjadi ketika pasien } \\
\text { dirawat di rumah sakit atau fasilitas medis lain, dan infeksi ini tidak } \\
\text { tersedia saat masuk. Setiap pasien rumah sakit berisiko terkena infeksi } \\
\text { yang didapat di rumah sakit. Keluarga pasien dapat menjadi perantara } \\
\text { yang dapat menyebarkan infeksi. Cuci tangan merupakan cara efektif } \\
\text { untuk memutus rantai infeksi. Kesalahan untuk melakukan cuci tangan } \\
\text { dengan benar dapat dianggap sebagai penyebab utama terjadinya infeksi } \\
\text { nosokomial di sarana kesehatan. Pemberian edukasi cuci tangan kepada } \\
\text { keluarga pasien harus dilakukan oleh seluruh civitas rumah sakit. } \\
\text { Peningkatan pemahaman keluarga pasien tentang cuci tanagn enam tahap } \\
\text { dapat berpengaruh terhadap perilaku mencuci tangan. Penelitian ini }\end{array}$ \\
\hline
\end{tabular}




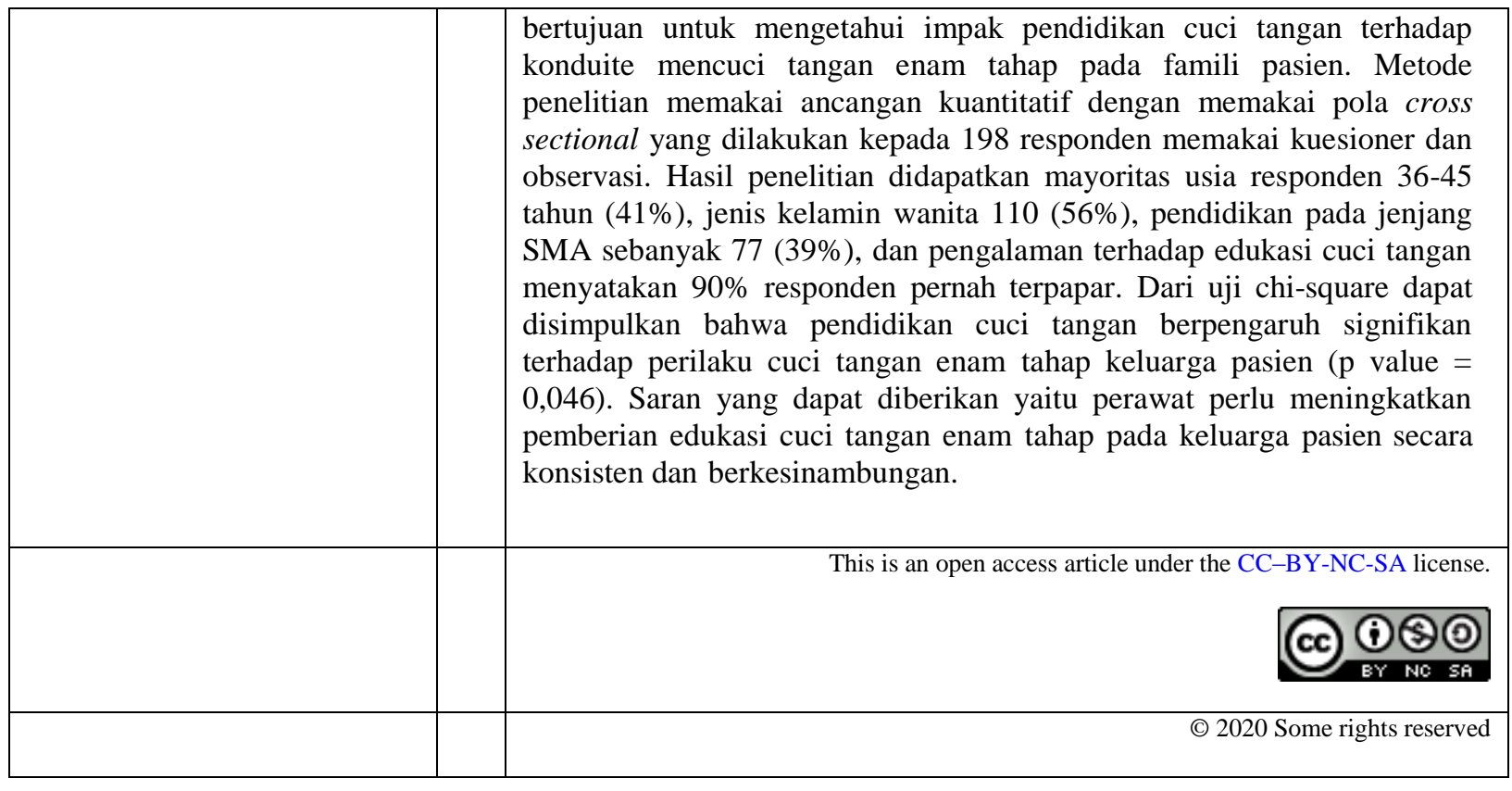




\section{PENDAHULUAN}

Rumah sakit adalah organisasi dengan kompleksitas yang sangat tinggi. Jenis kesalahan yang paling sering memicu kematian di setiap rumah sakit adalah infeksi nosokomial. Infeksi nosokomial mengacu pada infeksi yang terjadi saat pasien menerima perawatan di rumah sakit, yang tidak tersedia pada saat masuk rumah sakit. (Khan et al, 2017). Penularan infeksi ini dapat terjadi melalui kontak pasien dengan tenaga medis, dari pasien ke pasien, dari pasien ke pengunjung rumah sakit, maupun dari keluarga dan/atau tenaga medis kepada pasien. Media infeksi nosokomial dapat terjadi akibat pemasangan alat kesehatan, perilaku tenaga kesehatan, pasien dan para pengunjung yang tidak mematuhi perilaku pencegahan infeksi (Dewi, 2017).

Menurut data WHO tahun 2016, kejadian infeksi nosokomial pada semua pasien rawat inap sekitar $15 \%$. Penyebab kematian neonatal adalah infeksi nosokomial, kejadiannya sekitar 4-56\%, Asia Tenggara dan Afrika sub-Sahara, kejadian situasi ini sekitar 75\%. Sejumlah rumah sakit di AS melakukan survey di tahun 2014 dan hasilnya menunjukkan bahwa kejadian infeksi nosokomial di unit perawatan terjadi infeksi akut mencapai 722.000 , dan 75.000 orang pasien dengan infeksi nosokomial meninggal selama dirawat di rumah sakit-rimah sakit tersebut (CDC, 2016).

Infeksi nosokomial masih sering terjadi. Sebuah survei terhadap 231.459 pasien dari 947 rumah sakit di 30 negara Eropa pada tahun 2011-2012 mengungkapkan bahwa $5,7 \%$ pasien terkena infeksi nosokomial (Jenkins, 2017). Setiap pasien yang menjalani perawatan beresiko terpapar infeksi nosokomial.

Infeksi nosokomial di Indonesia sangat umum. Menurut data Kementerian Kesehatan (2011), kejadian infeksi nosokomial di Indonesia mencapai $15,74 \%$, jauh lebih tinggi dibandingkan di negara maju (4,8\% hingga $15,5 \%)$. Pada tahun 2013, Kementerian Kesehatan melakukan survei terhadap 10 rumah sakit pendidikan dan menemukan angka infeksi nosokomial sangat tinggi yaitu 6-16\% dengan rata-rata 9,8\% (Kemenkes RI, 2013). Ada 11 rumah sakit di wilayah Ibukota Jakarta yang ikut dalam survei dan menunjukkan bahwa 9,8\% dari pasien rawat inap mengalami infeksi baru. Hal ini menunjukkan bahwa 1 dari 10 pasien yang mendapat pengobatan akan mengalami infeksi nosokomial.

Pencegahan infeksi merupakan kunci keberhasilan program penanggulangan masalah ini. Salah satu 
cara paling efektif mencegah infeksi nosokomial adalah dengan cuci tangan. Beberapa cara untuk menghentikan kejadian infeksi salah satunya adalah dengan mencuci tangan dengan benar. Mencuci tangan yang tepat merupakan upaya pengendalian infeksi terdepan (Komisi Akreditasi Rumah Sakit, 2012). Oleh karena itu, supervisi, audit, promosi, dan edukasi tentang cuci tangan terusmenerus dilakukan secara berkesinambungan (Edwardson \& Cairns, 2018). Menurut Jenkins (2017) mencuci tangan secara benar dapat mengurangi jumlah bakteri patogen pada kedua tangan serta meminimalkan penularan infeksi secara silang.

Mencuci tangan merupakan salah satu tahap efektif untuk memutus rantai infeksi silang, yang dapat mengurangi kejadian infeksi nosokomial (Rahmawati \& Sofiana, 2017). Pelaksanaan kegiatan cuci tangan disesuaikan dengan tata cara standar untuk mencegah bakteri berkembangbiak. Upaya peningkatan kepatuhan perilaku cuci tangan harus dilakukan secara simultan tidak hanya kepada seluruh civitas rumah sakit, namun juga kepada pengunjung rumah sakit yang merupakan bagian dari rantai transmisi penyebaran infeksi. Cara mencuci tangan yang benar harus mengikuti enam tahap mencuci tangan dan lima waktu pencucian. Saat yang tepat untuk melakukan kegiatan mencuci tangan pakai sabun dan air ledeng adalah 40-60 detik. Saat menggunakan hand scrub, durasinya 20-30 detik. Hasil penelitian menunjukkan bahwa mencuci tangan dengan benar dapat menekan jumlah kejadian infeksi nosokomial hingga 20-40\%. (WHO, 2016).

Pendidikan kesehatan merupakan rangkaian kegiatan yang merencanakan secara sadar untuk menciptakan kesempatan untuk seseorang agar belajar memperbaiki kesadaran (literacy) dan memperluas wawasan serta keterampilan (life skills) demi kebutuhan kesehatannya (Notoatmodjo, 2012). Pengetahuan keluarga pasien tentang infeksi nosokomial dan pencegahannya yang didapatkan melalui edukasi cuci tangan merupakan rangsangan sosial yang dapat menyebabkan reaksi emosional terhadap upaya kewaspadaan universal, sehingga peran sertanya akan meningkat dalam usaha melindungi diri dari infeksi nosokomial (Damanik, Susilaningsih, \& Amrullah, 2012).

\section{METODE}

Desain penelitian ini mengadopsi metode cross sectional. Dalam periode waktu yang sama, hubungan antara 
pendidikan cuci tangan dan perilaku mencuci tangan di enam tahap di keluarga pasien diteliti dengan metode crosssectional. Metode ini dipilih karena relatif murah dan membutuhkan waktu yang lebih singkat, tetapi kejadian insiden dapat diperkirakan. Penelitian ini di Ph.D. Berlokasi di Jl. Sitanala Tangerang. Dr. Sitanara's 99 Kota Tangerang akan diadakan dari 16 Juni hingga 5 Agustus 2020. Pada April 2020, Sitanala Tangerang (Sitanala Tangerang) dikunjungi sebanyak 391 orang.

Berdasarkan perhitungan diperoleh menggunakan rumus Slovin diketahui jumlah sampel seluruhnya yaitu 198 responden. Sampel dalam penelitian ini diambil dengan memakai teknik nonprobability sampling. Teknik penentuan siapa yang menjadi sampel menggunakan metode convenience sampling yaitu keluarga pasien yang menjadi sampel sasaran berdasarkan kesempatan untuk bertemu dan berada di lokasi penelitian. Peneliti akan memberikan kuesioner kepada responden di setiap unit pelayanan rawat inap dan diberi waktu sekitar 30 menit untuk menjawab kuesioner tersebut. Pada penelitian ini kriteria inklusinya adalah dewasa (usia $\geq 17$ tahun), keluarga pasien rawat inap, dan setuju menjadi responden dengan memberi paraf pada formulir persetujuan. Sedangkan kriteria eksklusinya adalah jika keluarga pasien yang mengisi kuesioner tidak lengkap. Alat ukur dalam penelitian ini menggunakan kuesioner (angket) dan blangko isian observasi. Kuesioner berupa lembar pernyataan tentang edukasi cuci tangan enam tahap. Kuesioner yang digunakan dalam penelitian ini terbagi menjadi bagian A, B, dan C. Bagian A merupakan data demografi responden yang teridiri dari 7 pertanyaan. Bagian B adalah kuesioner tentang edukasi cuci tangan. Kuisioner ini terdapat 15 pernyataan yang akan diberikan kepada responden seteleh edukasi cuci tangan enam tahap. Bagian C merupakan formulir observasi cuci tangan enam tahap yang akan digunakan peneliti untuk menilai kesesuaian perilaku cuci tangan yang dilakukan responden.

Pada kuesioner edukasi cuci tangan, skala Likert digunakan oleh peneliti dengan rentang nilai 1 sampai 4 , dimana 1 = sangat tidak setuju; 2 = tidak setuju; 3 = setuju; 4 = sangat setuju; sedangkan untuk pernyataan negatif $4=$ sangat tidak setuju; $3=$ tidak setuju; $2=$ setuju; dan 1 = sangat setuju. Sebelum digunakan sebagai alat pengumpul data, kuisioner ini harus terlebih dahulu dianalisa kesahihan dan reliabilitasnya supaya hasil yang diperoleh sahih dan 
reliabel. Prosedur pengumpulan data dalam penelitian dilakukan dengan mengikuti prosedur administrasi dari Rumah Sakit kemudian melaksanakan prosedur penelitian kepada calon responden yang sesuai memenuhi kriteria sampel yang ditetapkan. Hasil data kemudian diolah melalui berbagai tahapan, diantaranya editing, pengkodean, penginputan data dan pengecekan ulang data masukan melalui software SPSS. Setelah data terkumpul akan dilakukan uji statistik untuk mengolah data sesuai dengan metode atau desain yang digunakan. Hasil data kemudian diuji dengan mengjkaji secara univariat dan bivariat.

\section{HASIL}

\section{Analisis Univariat}

Analisis univariat dilakukan untuk mendeskripsikan spesifikasi dari masing-masing variabel yang diteliti.

Tabel 1. Distribusi Frekuensi Responden Berdasarkan Usia, Jenis Kelamin, Pendidikan, Edukasi, Persepsi, dan Perilaku Cuci Tangan di Unit Rawat Inap RS dr. Sitanala Tahun 2020

\begin{tabular}{lcc}
\hline Usia & Frekuensi (n) & Prosentase (\%) \\
\hline$\leq 25$ tahun & 20 & 10 \\
$26-35$ tahun & 71 & 36 \\
$36-45$ tahun & 82 & 41 \\
$>45$ tahun & 25 & 13 \\
\hline Jenis Kelamin & \multicolumn{2}{c}{} \\
\hline Pria & 110 & 56 \\
Wanita & & 44 \\
\hline Pendidikan & 29 & 15 \\
\hline SD & 32 & 16 \\
SMP & 77 & 39 \\
SMA & 60 & 30 \\
Perguruan Tinggi & & 90 \\
\hline Edukasi Cuci Tangan & 178 & 10 \\
\hline Pernah & 20 & 70 \\
Belum & & 30 \\
\hline Persepsi Edukasi Cuci Tangan & 138 & \\
\hline Baik & 60 & 64 \\
Kurang & & 36 \\
\hline Perilaku Cuci Tangan 6 Tahap & 126 & $\mathbf{1 0 0}$ \\
\hline Melakukan & $\mathbf{1 9 8}$ & \\
Tidak melakukan & & \\
\hline \multicolumn{1}{c}{ Jumlah } & & \\
\hline
\end{tabular}

Seperti terlihat pada Tabel 1, mayoritas responden yang berusia 3645 tahun sebanyak 82 responden $(41 \%)$, dan sebanyak 20 responden $(10 \%)$ berusia minimal 25 tahun ke bawah. Mayoritas responden berjenis kelamin wanita sebanyak $110(56 \%)$, lebih banyak daripada responden pria yang 
berjumlah 88 (44\%). Jumlah responden berada pada jenjang pendidikan SMA sebanyak 77 (39\%), diikuti jenjang Perguruan Tinggi sebanyak 60 responden (30\%), jenjang SMP sebanyak 32 responden (16\%), dan jenjang SD sebanyak 29 responden $(15 \%)$.

Tabel 1 menunjukkan mayoritas responden dengan jumlah 178 (90\%) pernah mengikuti kegiatan edukasi cuci tangan enam tahap, sedangkan sisanya sebanyak 20 responden (10\%) belum pernah terpapar dengan edukasi cuci tangan. Edukasi cuci tangan tersebut dipersepsikan baik oleh 138 responden (70\%) dan sisanya dipersepsikan kurang oleh 60 responden $(30 \%)$. Perilaku cuci tangan 6 tahap didapatkan mayoritas responden telah melakukan cuci tangan 6 tahap dengan benar sebanyak 126 (64\%). Sedangkan yang tidak melakukan sebanyak 72 responden $(36 \%)$.

\section{Analisis Bivariat}

Metode uji statistik chi-square digunakan untuk analisis bivariat. Tabel 2 di bawah ini mencantumkan korelasi dan signifikansi antara variabel pendidikan mencuci tangan dan variabel enam tahap perilaku mencuci tangan dalam keluarga pasien.

Tabel 2. Hubungan Edukasi Cuci Tangan dengan Perilaku Cuci Tangan Enam Tahap di Unit Rawat Inap RS dr. Sitanala Tahun 2020

\begin{tabular}{|c|c|c|c|c|c|c|c|c|}
\hline \multirow{3}{*}{ Variabe } & & \multicolumn{4}{|c|}{$\begin{array}{c}\text { Perilaku Cuci Tangan } \\
6 \text { Tahap }\end{array}$} & \multirow{3}{*}{$\sum \mathrm{n}$} & \multirow{3}{*}{$\sum \%$} & \multirow{3}{*}{$p$} \\
\hline & & \multicolumn{2}{|c|}{ Melakukan } & \multicolumn{2}{|c|}{$\begin{array}{c}\text { Tidak } \\
\text { Melakukan }\end{array}$} & & & \\
\hline & & $\mathrm{n}$ & $\%$ & $\mathrm{n}$ & $\%$ & & & \\
\hline \multirow{2}{*}{$\begin{array}{c}\text { Edukasi Cuci } \\
\text { Tangan }\end{array}$} & Baik & 93 & 47 & 45 & 23 & 138 & 70 & \multirow{3}{*}{$0.046 *$} \\
\hline & Kurang & 33 & 17 & 27 & 13 & 60 & 30 & \\
\hline \multicolumn{2}{|l|}{ Total } & 126 & 64 & 72 & 36 & 198 & 100 & \\
\hline
\end{tabular}

*Bermakna pada $\alpha<0.05$

Bersumber pada hasil analisa bivariat antara variabel pendidikan cuci tangan terhadap perilaku mencuci tangan enam tahap dengan menggunakan uji chisquare diperoleh nilai signifikansi $\mathrm{p}=$ 0,046 ( $p$ value <0,05). Hal ini menunjukkan bahwa Ho (hipotesis nol) ditolak dan $\mathrm{Ha}$ (hipotesis substitusi) diterima, sehingga terdapat hubungan antara pendidikan cuci tangan dengan perilaku cuci tangan enam tahap pada keluarga pasien di rumah sakit dr. Sitanala Tangerang. 


\section{PEMBAHASAN}

\section{Analisis Univariat}

Hasil analisis menunjukkan bahwa sebagian besar responden berusia antara 36-45 tahun, hingga 41\%. Usia paling sedikit yaitu kurang dari sama dengan 25 tahun sebanyak 10\%.Usia 26-35 tahun sebanyak 36\% dan usia > 45 tahun sebanyak 13\%. Pembagian kelompok usia dilakukan peneliti berdasarkan Depkes, 2009. Hasil ini didukung oleh Firdausy, Riyanti, \& Husodo (2016) yang melakukan penelitian tentang penggunaan tisu basah disinfektan pada pengawas pasien menunjukkan bahwa mayoritas responden berusia antara 26-45 tahun $(53,5 \%)$. Penelitian lain yang bertema infeksi nosokomial menunjukkan usia mayoritas responden berada pada rentang 33-46 tahun dengan jumlah 45\% merupakan mayoritas (Abubakar \& Nilamsari, 2017). Kedewasaan berkaitan dengan mempelajari pengetahuan baru, kemampuan pengetahuan, luasnya pengalaman dan jumlah keterampilan yang dipelajari. Keberagaman hasil penelitian ditemukan ketika menyelidiki keterkaitan antara usia dengan faktor lain. PenelitianKooij et al., (2011) meyakini bahwa usia berhubungan dengan faktor kecerdasan dan kemampuan belajar yang cenderung menurun seiring penambahan usia. Sifat kepribadian seseorang dapat berubah selama rentang usia kehidupan dan pada gilirannya dapat menimbulkan perubahan sikap dalam mempelajari hal baru (Ng \& Feldman, 2009). Peneliti juga berpendapat bahwa usia identik dengan semakin matangnya pola pikir dan kemapanan emosional. Meningkatnya usia akan berdampak pada kemampuan berpikir rasional. Pemberian edukasi cuci tangan dan permasalahan infeksi akan menjadi materi diskusi yang menarik yang ingin diketahui oleh orang dewasa.

Hasil analisis memperlihatkan bahwa sebagian besar responden adalah wanita sebanyak $110 \quad(56 \%)$, sedangkan responden pria sebanyak $88 \%(44 \%)$. Hal ini sesuai dengan penelitian Iskandar \& Yanto (2018) yang menunjukkan bahwa jenis kelamin sebagian besar responden berjenis kelamin wanita, $85 \%$ pada kelompok intervensi dan $60 \%$ pada kelompok kontrol. Selain itu, penelitian Iskandar \& Yanto (2018) mengaitkan jenis kelamin dengan pelaksanaan cuci tangan pada 6 tahapan dan 5 momen di keluarga pasien, didapatkan $p$-value $=$ 0,155. Kesimpulannya adalah tidak ada kaitan antara jenis kelamin dengan pelaksanaan mencuci tangan. Dalam istilah gender, gender menggambarkan karakteristik tertentu. Pada umumnya 
wanita lebih perhatian terhadap pasien dan lebih perduli dalam memenuhi kebutuhan pasien. Namun, ketika dihubungkan dengan pengetahuan perilaku cuci tangan, peneliti tidak menemukan signifikansi hubungan.

Hasil analisis menunjukkan mayoritas responden berada pada jenjang pendidikan SMA sebanyak 77 (39\%), dan yang paling sedikit adalah jenjang pendidikan SD sebanyak 29 responden (15\%). Hasil ini didukung oleh penelitian Iskandar \& Yanto (2018) yang mendapatkan 50\% responden pada kelompok kontrol berpendidikan SMA. Lebih lanjut penelitian ini menghubungkan pendidikan dengan perilaku cuci tangan dengan hasil p-value sebesar 0.119 yang berarti tidak terdapat hubungan. Tingkat pendidikan merupakan salah satu karakteristik yang memengaruhi pengetahuan, sikap dan kompetensi seseorang. Peneliti berpendapat bahwa tingkat pendidikan seseorang dapat berpengaruh terhadap pengetahuan secara umum. Namun tidak spesifik terhadap tema edukasi dan perilaku cuci tangan. Rasa ingin tahu dan motivasi untuk mencari informasi tentang pencegahan infeksi nosokomial dan perilaku cuci tangan, lebih memberikan kontribusi ketimbang tingkat pendidikan itu sendiri.
Hasil perhitungan pada tabel 1 menunjukkan bahwa mayoritas responden dengan jumlah 178 (90\%) pernah mengikuti kegiatan edukasi cuci tangan enam tahap, sedangkan sisanya sebanyak 20 responden (10\%) belum pernah terpapar dengan edukasi cuci tangan. Pengalaman merupakan suatu kejadian ditangkap oleh alat indera dan menyimpannya di dalam ingatan. Bisa dari kejadian yang baru saja terjadi ataupun yang sudah berlangsung lama, pengalaman bisa didapat atau dirasakan. Pengalaman dapat diartikan sebagai ingatan sementara, yang dapat menerima dan memuat kejadian yang dialami seseorang pada waktu dan tempat tertentu, dan dijadikan riwayat hidup. (Notoatmojdo, 2012).

Hasil penelitian menunjukkan pemberian edukasi cuci tangan pada kategori baik sebanyak $70 \%$. Sedangkan pada kategori kurang sebanyak $30 \%$. Hasil penelitian lain menunjukkan bahwa pengetahuan responden meningkat ratarata 14,53 dan setelah diberikan edukasi menjadi 16,93 (Sanyati \& Santoso, 2015). Keluarga pasien merupakan salah satu faktor sebagai media penularan penyakit. Pemberian edukasi tentang cuci tangan enam tahap menggunakan cairan berbasis alkohol/air mengalir dapat meningkatkan 
pemahaman keluarga pasien dalam memutuskan mata rantai infeksi. Hasil analisis yang dilakukan Firdausy, Riyanti \&Husodo (2016) menyimpulkan bahwa $70 \%$ responden mengungkapkan tidak tersedianya informasi tentang cuci tangan. Peneliti meyakini bahwa edukasi bisa dilakukan secara langsung maupun tidak langsung dengan memasang slogan atau spanduk yang mengajak cuci tangan.

Hasil analisis menunjukkan 64\% responden melakukan perilaku cuci tangan enam tahap. Penelitian Sanyati \& Santoso (2015) menyimpulkan perilaku cuci tangan keluarga pasien berada pada kategori tidak melakukan cuci tangan sebanyak $81,7 \%$. Penelitian lain tentang gambaran pelaksanaan cuci tangan pengunjung bangsal dengan responden sebanyak 105 pengunjung, menyimpulkan bahwa 28 pengunjung tidak benar melakukan perilaku 6 tahap cuci tangan menggunakan air mengalir, dan 49 pengunjung tidak benar melakukan prosedur 6 tahap cuci tangan menggunakan handrub (Karala \& Kurniasari, 2015).

Hasil analisis deskriptif menunjukkan bahwa sebagian besar (80\%) pengunjung tidak mencuci tangan sebelum masuk ruang operasi, dan sebagian besar $(81,82 \%)$ pengunjung tidak mencuci tangan setelah memasuki ruang operasi.
$64 \%$ dari pengunjung di ICU tidak mencuci tangan saat masuk ke dalam ruangan dan menyatakan bahwa patogen di tangan mereka positif (Theresia, 2017). Keadaan ini menunjukkan bahwa pengunjung / keluarga pasien adalah perantara infeksi nosokomial pada pasien yang rawan di ICU. Kebersihan tangan adalah elemen inti dalam melindungi pasien dari infeksi HAI / rumah sakit. Mengikuti aturan enam tahap, mudah untuk menggosok tangan dengan disinfektan jenis alkohol / air keran dan hanya membutuhkan waktu beberapa detik (Rikayanti \& Arta, 2014). Pada umumnya keluarga pasien/ pengunjung sudah terpapar dengan edukasi cuci tangan melalui banner yang terpasang di sudutsudut rumah sakit, namun adakalanya keluarga pasien belum menerapkannya. Rumah sakit menyediakan berbagai metode cuci tangan di setiap ruang rawat inap, seperti wastafel cuci tangan dan hand sanitizer. Cobalah untuk mengoptimalkan perilaku mencuci tangan keluarga pasien. Peran perawat adalah mengingatkan keluarga pasien untuk tidak lupa mencuci keenam langkah tersebut, sehingga kebiasaan cuci tangan menjadi sebuah kebiasaan (habit). Perilaku seseorang ditentukan atau dibentuk oleh beberapa faktor, seperti pengetahuan, 
sikap, emosi, dan kognisi. Perasaan adalah bagian yang tak terpisahkan dari emosi. (Notoatmodjo, 2010). Pemberian pengetahuan melalui edukasi yang terus menerus pada keluarga pasien diharapkan memberikan dampak positif pada perilaku cuci tangan enam tahap.

\section{Analisis Bivariat}

Hasil analisis korelasi statistik memperlihatkan bahwa terdapat kaitan yang bermakna antara pendidikan cuci tangan dengan perilaku cuci tangan pada keluarga pasien, dengan nilai 0,046 . Hal tersebut sejalan dengan riset yang dilakukan oleh Iskandar \& Yanto (2018) yang menunjukkan bahwa keluarga pasien di RSUD Roemani Muhammadiyah Semarang mendapatkan 5 penyuluhan kesehatan dalam 6 tahap yang berdampak signifikan terhadap perilaku cuci tangan. (Nilai $\mathrm{P}=0,001)$. Penelitian lain menunjukkan bahwa pendidikan cuci tangan berpengaruh signifikan terhadap tingkat pengetahuan keluarga pasien di RSU Ungaran ( $p$ value $<0,05$ ) (Sanyati \& Santoso, 2015). Tingkat pengetahuan merupakan salah satu aspek yang menyebabkan perilaku mencuci tangan. Pengetahuan adalah jati diri yang utama untuk perilaku kreatif. Dengan memberikan edukasi cuci tangan bagi anggota keluarga pasien maka bisa menambah pengetahuan dan perilaku cuci tangan sehingga meningkatkan pengalaman dan wawasan khususnya informasi tentang cuci tangan.

Upaya peningkatan pengetahuan melalui metode pendidikan. Pendidikan kesehatan merupakan proses yang direncanakan secara sadar yang bertujuan untuk menciptakan kesempatan bagi individu untuk terus belajar meningkatkan pengetahuan (literasi), pengetahuan dan kecakapan hidup, sehingga bermanfaat bagi kesehatannya sendiri. (Nusalam, 2017). Penggunaan teknik orasi, peragaan dan bimbingan merupakan salah satu upaya untuk menambah wawasan, dan perilaku keluarga tentang manfaat mencuci tangan dengan benar di kawasan rumah sakit. (Iskandar \& Yanto, 2018).

Penelitian yang dilakukan ECCMID di Australia menunjukkan pengaruh signifikan antara perilaku cuci tangan dalam pengurangan angka infeksi di rumah sakit. Penelitian ini menyimpulkan bahwa setiap peningkatan $10 \%$ kepatuhan kebersihan tangan, adapenurunan 15\% terkait kejadian infeksi aliran darah Staphylococcus aureus di 132 rumah sakit besar di Australia (ECCMID, 2020). Kepatuhan merupakan hasil perilaku yang 
dibentuk secara berkesinambungan. Agar dapat bereperilaku cuci tangan secara benar maka keluarga pasien perlu mendapatkan edukasi tentang cuci tangan dari petugas kesehatan di rumah sakit. Hasil penelitian ini memberikan peringatan bahwa perilaku cuci tangan akan menurun pada saat bimbingan/kontrol tidak dilakukan. Perawat memiliki peran untuk terus mengingatkan pasien dan keluarga agar melakukan perilaku cuci tangan. Pemberian edukasi tentang cuci tangan dalam situasi informal merupakan strategi yang dapat digunakan perawat. Kegiatan edukasi dapat meningkatkan pengetahuan keluarga pasien, yang akan mengarah pada sikap dan pada akhirnya menumbuhkan perilaku individu atau kelompok berdasarkan kesadaran dan kemauan individu untuk melakukan cuci tangan enam tahap.

\section{KESIMPULAN}

Hasil penelitian dan pembahasan dalam penelitian mengenai pengaruh edukasi cuci tangan dengan perilaku cuci tangan enam tahap pada keluarga pasien dapat disimpulkan bahwa karakteristik menunjukkan bahwa mayoritas usia berada pada rentang usia 36-45 tahun sebanyak 82 responden (41\%), jenis kelamin wanita sebanyak 110 (56\%), pendidikan pada jenjang SMA sebanyak 77 (39\%), dan pengalaman terhadap edukasi cuci tangan menyatakan 178 responden (90\%) pernah terpapar. Distribusi frekuensi berdasarkan edukasi cuci tangan enam tahap didapatkan 138 responden $(70 \%)$ menyatakan baik, dan sisanya sebanyak 60 responden $(30 \%)$ menyatakan kurang. Distribusi frekuensi berdasarkan perilaku cuci tangan enam tahap didapatkan responden yang melakukan cuci tangan enam tahap berdasarkan observasi peneliti sebanyak 126 responden (64\%), sedangkan yang tidak melakukan sebanyak 72 responden (36\%). Hasil analisa bivariat memperlihatkan bahwa ada kaitan antara variabel pendidikan cuci tangan di fasilitas rawat inap dengan enam tahap perilaku cuci tangan keluarga pasien selama diirawat di RS dr. Sitanala Tangerang (nilai $\mathrm{p}=0,046$ ).

\section{DAFTAR PUSTAKA}

Abubakar, N. \& Nilamsari, N. Pengetahuan dan Sikap Keluarga Pasien Rawat Inap Rumah Sakit Haji Surabaya terhadap Pencegahan Infeksi Nosokomial. Jurnal Manajemen Kesehatan. 2017: 3(1) 4961.

Almalki, S. Integrating Quantitative and Qualitative Data in Mixed Methods Research - Challenges and Benefits. 
Journal of Education and Learning. 2016: 5(3), 288-296.

CDC. National and State Healthcare Associated Infections Progress Report. 2016.

Damanik, S. R., Susilaningsih, F. S., Amrullah, A. A. Kepatuhan Hand Hygiene di Rumah Sakit Immanuel Bandung. Student e-Journal. 2012: 8(2) $1-14$.

Depkes. Pedoman Manajerial Pencegahan dan Pengendalian Infeksi di Rumah Sakit dan Fasilitas Pelayanan Kesehatan Lainnya; 2011.

Dewi, R. R. K. Faktor Determinan Kepatuhan Perawat dalam Melakukan Praktik Cuci Tangan di RSUD Ade Muhammad Djoen Sintang. Jurnal Kesehatan Masyarakat Khatulistiwa. 2017: 4(3), 232-237.

Edwardson, S., \& Cairns, C. Nosocomial infections in the ICU. Anaesthesia and Intensive Care Medicine. 2018: 20(1), 14-18.

European Congress of Clinical Microbiology $\&$ Infectious Diseases (ECCMID). Clinical Microbiology and Infection; 2020 25(8) 1021-1025.

Firdausy, D.A., Riyanti, E., \& Husodo, B.T. Faktor-Faktor yang Berhubungan dengan Perilaku Penggunaan Antiseptic Handrub pada Penunggu Pasien Rawat Inap di Bangsal Dahlia Kelas III RSUD Kabupaten Brebes. Jurnal Kesehatan Masyarakat, 2016: 4(5) 56-64.

Iskandar, M. B., \& Yanto, A. Pengaruh Pendidikan Kesehatan terhadap Pelaksanaan Cuci Tangan 6 Tahap 5 Momen Keluarga Pasien di Ruang Rawat Inap RS Roemani Semarang. Prosiding Seminar Nasional Mahasiswa Unimus. 2018: Vol. 1. e-ISSN: 2654-766X. 120128
Jenkins, D. R. (2017). Nosocomial Infections and Infection Control Key Points. 2017: $1-5$.

doi.org/10.1016/j.mpmed.2017.07.005

Karala, A. Gambaran Pelaksanaan Cuci Tangan Pengunjung di Bangsal Ar Royan RS PKU Muhammadiyah Yogyakarta. Thesis. 2015.

Kemenkes RI. Pedoman Manajerial Pencegahan dan Pengendalian Infeksi di Rumah Sakit dan Fasilitas Pelayanan Kesehatan Lainnya. Direktorat Jenderal Bina Pelayanan Medik. Jakarta; 2013.

Khan, H. A., Baig, F. K., \& Mehboob, R. Nosocomial Infections: Epidemiology, Prevention, Control and Surveillance. Asian Pacific Journal of Tropical Biomedicine. 2017: 7(5), 478-482.

Komisi Akreditasi Rumah Sakit (KARS). Panduan Penilaian Survei Akreditasi Rumah Sakit. Jakarta; 2012.

Kooij, D. T. A. M., Lange, A. H. D., Jansen, P. G. W., Kanfer, R., \& Dikkers, J. S. E. (2011). Age and work-related motives: Results of a meta-analysis. Journal of Organizational Behavior. 2011 3(2) 197-225.

Mumpuningtias, E.D., Aliftitah, S., \& Illiyani. Hubungan Tingkat Pengetahuan dengan Perilaku Cuci Tangan Menggunakan Handrub pada Keluarga Pasien di Ruang Bedah RSUD Dr. Moh. Anwar Sumenep. Jurnal Keperawatan STIKes Hang Tuah Surabaya. 2017: 12(2) 1176- 1181.

Ng, T. W. H., \& Feldman, D. C. Age , work experience, and the psychological contract. Journal of Organizational Behavior. 2009: 1075(March), 10531075. 
Notoatmodjo, S. Metodologi Penelitian Kesehatan. Jakarta: PT Rineka Cipta; 2015.

Nursalam. Metode Penelitian Ilmu Keperawatan. Edisi 4. Jakarta: Salemba Medika; 2017.

Rahmawati, S., \& Sofiana, L. Pengaruh Metode Hand Wash terhadap Penurunan Jumlah Angka Kuman pada Perawat Ruang Rawat Inap di RSKIA PKU Muhammadiyah Kotagede Yogyakarta. IKAKESMADA; 2017 69-74.

Rikayanti, Kadek, H., Arta, S. K. Hubungan Tingkat Pengetahuan dengan Perilaku Mencuci Tangan Petugas Kesehatan di Rumah Sakit Umum Daerah Badung. Artikel Penelitian. Ilmu Kesehatan Masyarakat Fakultas Kedokteran Universitas Udayana. 2014.

Sanyati, D., \& Santoso, A. Pengaruh Edukasi Cuci Tangan Terhadap Tingkat Pengetahuan Keluarga Pasien di RSUD Ungaran. e-journal Undip. 2015.

Solely, G., Handiyani, H., \& Nuraini, T. Peningkatan Pengetahuan dan Kepatuhan Melakukan Kebersihan Tangan melalui Pelatihan dengan Fluorescence Lotion. Jurnal Keperawatan Indonesia. 2015; 18(2), 123-131.

Theresia, S. I. M. Perilaku Mencuci Tangan Pengunjung Rumah Sakit di Rumah Sakit Swasta Yogyakarta. Media Ilmu Kesehatan; 2017 6(3), 213- 217.

World Health Organization. The burden of health care-associated infection world wide. 2016. 